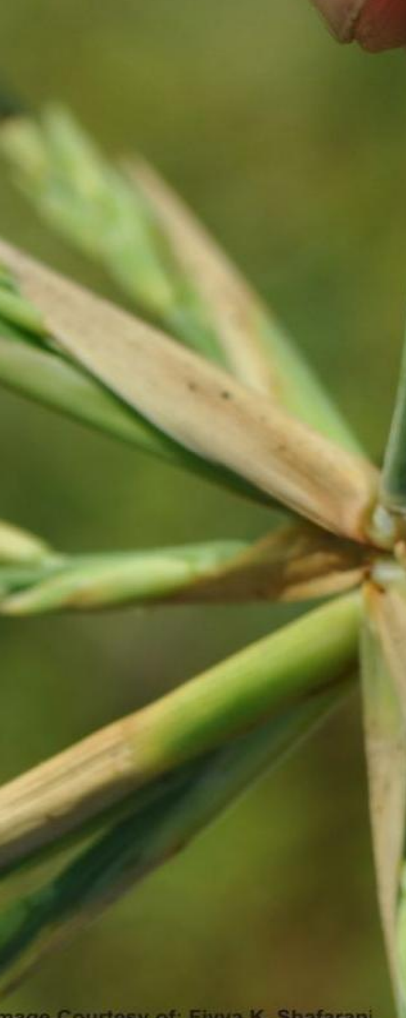

\title{
PIROCEIEIDINGS OF
} THE $6^{\text {th }}$ INDONESIA-JAPAN JOINT SCIENTIFIC SYMPOSIUM Qtge. 2014

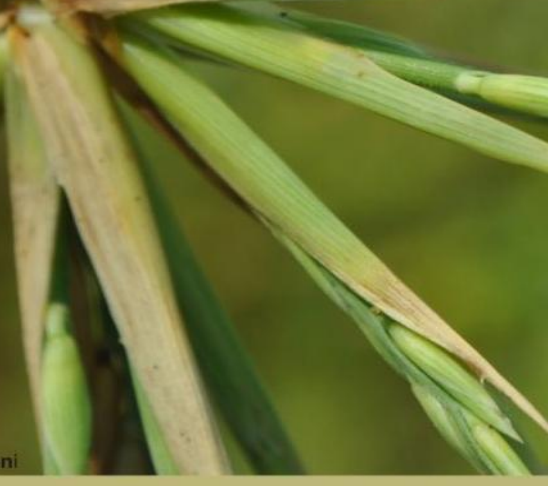

University Club (UC), Universitas Gadjah Mada, Yogyakarta, Indonesia
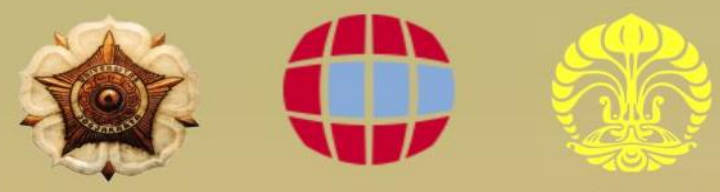

UNIVERSITAS

CHIBA
UNIVERSITY

UNIVERSITAS

INDONESIA

\section{Editors:}

Muh Aris Marfai

Dyah R. Hizbaron

Estuning Tyas W. Mei

Badan Penerbit Fakultas Geografi (BPFG) UGM 


\section{Foreword}

The $6^{\text {th }}$ Indonesia Japan Joint Scientific Symposium (IJJSS) 2014 is organized by Chiba University (Japan); University of Indonesia (Indonesia); and Universitas Gadjah Mada (Indonesia). The 6th IJJSS 2014 will be held in Universitas Gadjah Mada on October 29th-30th 2014. The symposium invites multidisciplinary studies. 26 topics will be discussed in this symposium, they are Antenna and Microwave, Architecture, Agriculture, Biomedical, Chemistry, Coastal and Watershed Management, Computer and Information Technology, Disaster Management, Electronic Circuit, Energy and Power System, Environmental Chemistry, Environmental Science, Humanities, Image and Signal Processing, Industrial Design and management, Mathematics, Mechanical Engineering, Mechatronics and Control, Medicine, Microsatellite and UAV, Nursing, Pharmacy, Remote Sensing and Geo-Information Science, Social Sciences and Sustainabilities, Socioeconomic Relations, and Vision \& Biological Functions. This Symposium aims are to provide a meeting that will enforce progress, stimulate growth, and advance the state of knowledge between students and researchers from Indonesia and Japan. Also this event provides a forum for discussion of new ideas, research, development and applications, including techniques and method to stimulate and inspired pioneering works.

All abstracts received in this time for publication have been reproduced here exactly as provided by the authors. Thus, the materials are the responsibility of specific authors and not of Organized Committee or the sponsoring organizations. English were designated official language for the 6th IJJSS 2014. Similarly, the abstracts provided here also in English at the discretion of the authors involved.

Last, we are sorry for any shortcomings. Thanks.

Yogyakarta, October 2014

The Committee 


\section{Conference organization}

\section{General chairman:}

Prof. Dr. rer. nat. Muh. Aris Marfai, M.Sc

\section{Steering committee:}

Prof. Dr. Junun Sartohadi, M.Sc.

drg. Ika Dewi Ana, Ph.D.

Dr. Sukamdi, M.Sc.

Drs. Projo Danoedoro, M.Sc., Ph.D.

Dr. Dyah Rahmawati Hizbaron, M.T., M.Sc.

Dr. Danang Sri Hadmoko, M.Sc.

Muhammad Edhie Purnawan, SE, MA, PhD.

\section{Sponsor:}

Chiba Shoyu Co., Ltd.

Kanto Electronic Corporation

Try International Inc. 


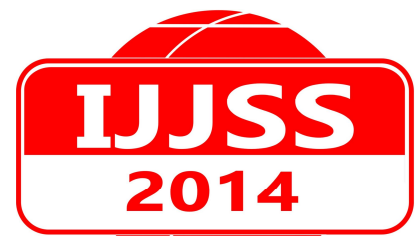

IJJSS 2014 : The 6th Indonesia Japan Joint Scientific Symposium

Yogyakarta, 28-30 October 2014

Theme code: I1

\title{
Flood Potential Prediction System Based on Water Level Image
}

\author{
Indra Riyanto* and Akhmad Musafa \\ Budi Luhur University, Jl. Cileduk Raya, Jakarta Selatan 12260, Indonesia
}

\begin{abstract}
In this research, a Flood Potential Prediction System is designed based on Water level Data obtained by image processing. The system process the output data from water level image into tables and then displayed as flood prediction image with a GIS program. The system processes the data in real time to provide public users the accurate flood area prediction. By using this system, user can predict the area which will be affected when the water level rises. Having this information allows the user to inform the peoples that live near the affected area to evacuate or at least to prepare for the upcoming flood. This kind of early warning system not only will save the life of people who live near the affected area but also save their valuables from the flood disaster. The area is segmented by ground elevation at $0.5 \mathrm{~m}$ intervals and water level is recorded at $10 \mathrm{~cm}$ intervals. The resulting area obtained from elevation data is considered as the boundary of the maximum extent of the flood. The plot of target area shows that an increase of $50 \mathrm{~cm}$ in river level can result in doubled area that possibly flooded, while increase of 1 meter of water level shows that the potential area grow fourfold than in normal condition.
\end{abstract}

\section{Keywords}

Sluice gate; river; water level; flood potential prediction; online system

\section{Introduction}

Flood is a natural phenomenon that occurs because the water volume in the channel, hence: canals, rivers, streams, surpass the capacity of the channel itself. It can also caused by the poor quality of the drainage in an area. Flood disasters cause significant material loss as well as psychological effect for the affected community. It also spawns further past-disaster problems like health problems, diseases, and also logistical problems. Many efforts have been undertaken by the government and by the community itself to address this problem, but all of these efforts will not function effectively without prior knowledge about the coming of the flood and the potentially affected areas. To

\footnotetext{
${ }^{*}$ Corresponding author. Tel.: +62-815-900-2864; fax: +62-21-7371164.

E-mail address: indra.riyanto@budiluhur.ac.id
} 
provide early warning for the incoming flood, many systems has been developed utilizing microcontroller or microprocessor-based electronic systems combined with a variety of level sensors to detect the water level of the nearby river that potentially floods an area. Most flood early warning systems only provides information that flood is imminent, but not the area that would be flooded, therefore, the information about the affected area is not sufficiently reach the community and the general public. With the advances in Information and Communication Technology (ICT), all concerned parties can utilize the technology to develop a system to predict areas with flood potentials. Website is one of the effective forms for information dissemination, which can come in messages, graphs, maps and images, utilizing river water level data obtained from sensors located at sluice gates as the input, the resulting information is expected to be always up to date (Wihartini et al, 2012). The purpose of this research is to develop flood area potential prediction system based on water level image of nearby river. This method is expected to provide near real time information.

\section{Remote Sensing and Image Processing}

\subsection{Remote Sensing}

Remote Sensing is defined as a science to obtain information about objects with the data analysis obtained from remote sensing devices. Generally, remote sensing is used to identify the surface of the object by the means of electromagnetic radiation that reflected or emitted by the object's surface. Every object on earth surface not only reflects or scatters part of incident electromagnetic energy but also emits radiation according to its temperature and emissivity. The detection and discrimination of objects or earth surface comprises of detecting and recording of radiated energy reflected or emitted by the objects or surface materials. Different objects will give different value and type in electromagnetic spectrum. Remote sensing system using sensors can be passive or active in nature. Active sensor system uses energy emitted by the platform itself, while a passive sensor depends on the object's emission or illumination from the sun. Optical image data is obtained by passive sensor system, while surface contour data and radar images are obtained from active sensors.

DEM is a digital representation of the surface topography. DEM found many use in geographic information system and became the basis of most digital relief mapping process. In digital mapping, each part of the map is divided into blocks. The gradient in each block is irregular that it needed to minimize the gradient variability in one block. Theoretically, this variability can be reduced by reducing the gradient angle interval used as block-dividing criteria. Practically, smaller interval increases the difficulty in the mapping process (Kristijono, 1994).

\subsection{Image Processing}

Digital image processing methods stems from two principal application areas: improvement of pictorial information for human interpretation; and processing of image data for storage, transmission, and representation for autonomous machine perception. An image may be defined as a two-dimensional function, $\mathrm{f}(\mathrm{x}, \mathrm{y})$, where $\mathrm{x}$ and $\mathrm{y}$ are spatial (plane) coordinates, and the amplitude of $f$ at any pair of coordinates $(x, y)$ is called the intensity or gray level of the image at that point. When $\mathrm{x}, \mathrm{y}$, and the amplitude values of $\mathrm{f}$ are all finite, discrete quantities, the image is called a digital image (Gonzalez et al, 2002). In 
the field of remote sensing, image analysis is done on digitally represented images with overhead perspective; since it is represented in numerical value, the image can be easily manipulated.

Image segmentation process subdivides an image into its constituent regions or objects. Segmentation process should stop when the objects of interest in an application have been identified, there is no point in carrying segmentation past the level of detail required to identify those elements. Segmentation of nontrivial images is one of the most difficult tasks in image processing. Segmentation accuracy determines the eventual success or failure of computerized analysis procedures. Image segmentation algorithms are generally based on one of two basic properties of intensity values: discontinuity and similarity. In the first category, the approach is to partition an image based on abrupt changes in intensity, such as edges in an image. In digital image there are three kinds of discontinuities: point discontinuity, line discontinuity, and edge discontinuity. The principal approaches in the second category are based on partitioning an image into regions that are similar according to a set of predefined criteria.

In this section we discuss an approach based on the concept of the socalled morphological watersheds. Segmentation by watersheds embodies many of the concepts of detection of discontinuities, thresholding, and region processing, and, as such, often produces more stable segmentation results, including continuous segmentation boundaries. This approach also provides a simple framework for incorporating knowledge-based constraints in the segmentation process. The concept of watersheds is based on visualizing an image in three dimensions: two spatial coordinates versus gray levels. In such a "topographic" interpretation, we consider three types of points: (a) points belonging to a regional minimum; (b) points at which a drop of water, if placed at the location of any of those points, would fall with certainty to a single minimum; and (c) points at which water would be equally likely to fall to more than one such minimum. For a particular regional minimum, the set of points satisfying condition (b) is called the catchments basin or watershed of that minimum. The points satisfying condition (c) form crest lines on the topographic surface and are termed divide lines or watershed lines. The principal objective of segmentation algorithms based on these concepts is to find the watershed lines.

One of the principal applications of watershed segmentation is in the extraction of nearly uniform (blob like) objects from the background. Regions characterized by small variations in gray levels have small gradient values. Thus, in practice, we often see watershed segmentation applied to the gradient of an image, rather than to the image itself. In this formulation, the regional minima of catchments basins correlate nicely with the small value of the gradient corresponding to the objects of interest. 


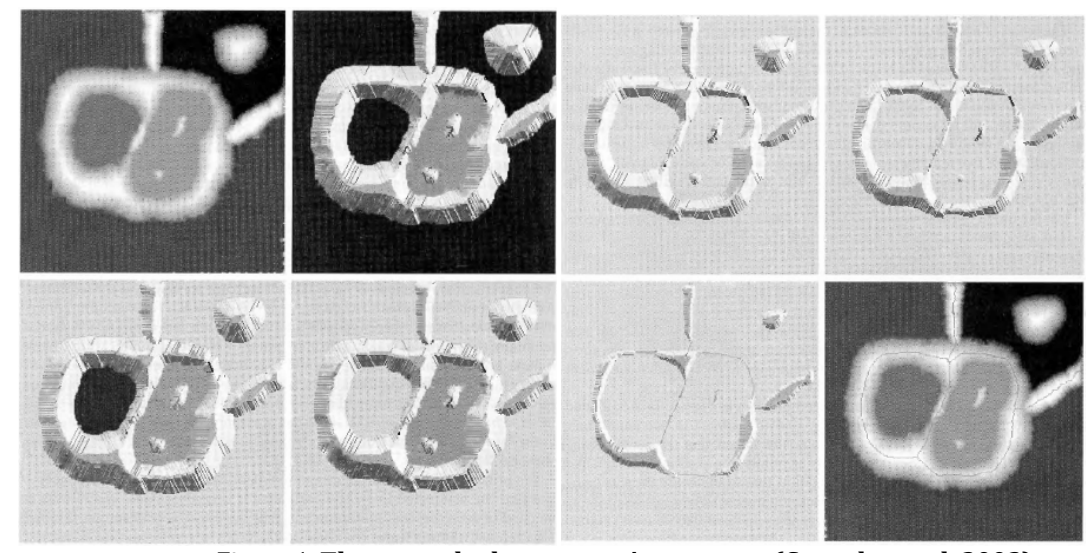

Figure 1. The watershed segmentation process (Gonzalez et al, 2002)

In Figure 1, top left image shows the basic image to be segmented, the next image shows the distance transformation for each pixel of the object, which now shows a ridge-like pattern. The next images shows the steps of "submerging", which is converting the value of the objects' outermost pixel (i.e. end of ridges) to that of the background's. the bottom left shows the watershed lines of the object. This line then superimposed to the original image as shown in the bottom right image.

\section{Jakarta Watershed Characteristics}

Land gradient in Jakarta area is relatively homogeneous, but in some places there are gradients of $4^{\circ}$ to $20^{\circ}$ which is typically in the southern part and on the riverbanks [6]. The flatness of the area is also evident in the rivers that flow through downtown Jakarta, which has many meanders. With generally low elevation and some areas being lower than sea level, and passed by 14 rivers with dendrite pattern, Jakarta is naturally very prone to flooding. This problem has been addressed by the Dutch colonial government by digging flood canal to the south and west of the then-Batavia city by diverting some flow of the Ciliwung River before entering Batavia to the west of the city before discharged to the sea. This canal, commonly caled Banjir Kanal Barat (west Banjir Kanal), is now absorbed by the growth of Jakarta and located in Central Jakarta Municipality. Recently, the government of Jakarta Special Capital Region completed the second flood canal to the east of the city. These canals are expected to absorb most of the river overflows that can cause floods in downtown areas.

Other than the canals, Jakarta public works service also maintains drainage system to minimize flood occurrence, it comprises of rivers and streams as main drainage system, complemented by a system of gates and pump installations to regulate the river flow. The pumps are also used to move excessive deposit of river flow to main drainage system and/or to artificial reservoirs which acts as water catchments area.

\section{Discussion}

\subsection{Flood Area Segmentation}

For the west Banjir Kanal area, the land elevation data is being made into grid pattern of the surface to obtain the surface contour with elevation resolution of 2 meters. The contour shown in Figure 2 is relatively homogenous 
since the canal is located in central flatland. Wide areas with low elevation located to the north of the observation area indicate low flatlands, while some low elevation areas to the south located along the riverbank.

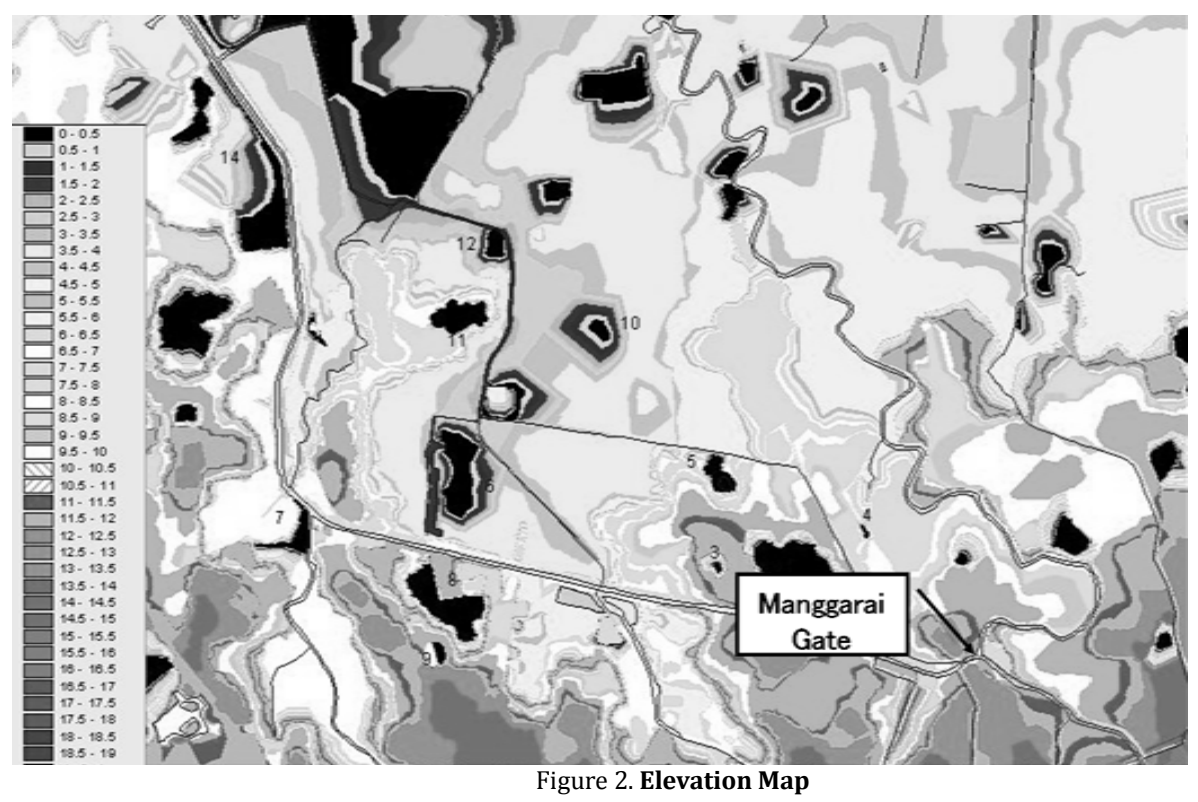

The specific sample area of interest is located at the lower right of the elevation map, with Manggarai Gate as its control point, shown as satellite image in Figure 3. This area is a densely populated residential area with some commercial buildings to the north and south.

\section{Sample Area}

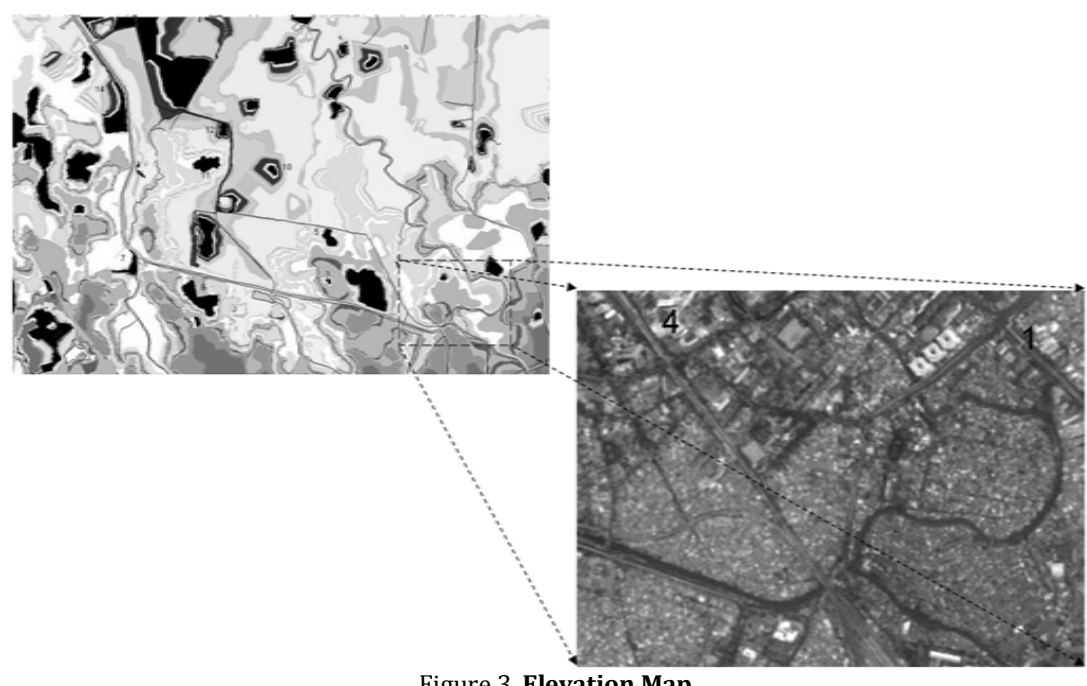

Figure 3. Elevation Map

The contour data is segmented with watershed segmentation method to find the watershed boundary pattern. This pattern is shown in Figure 4, in which, when the water level at Manggarai Gate is at normal condition, that is, $750 \mathrm{~cm}$ or less, there is already potential flood areas due to its elevation being much lower than the riverbed. In the sample area of Pegangsaan sub district, there is already 0.446 hectares of potentially flooded area. 


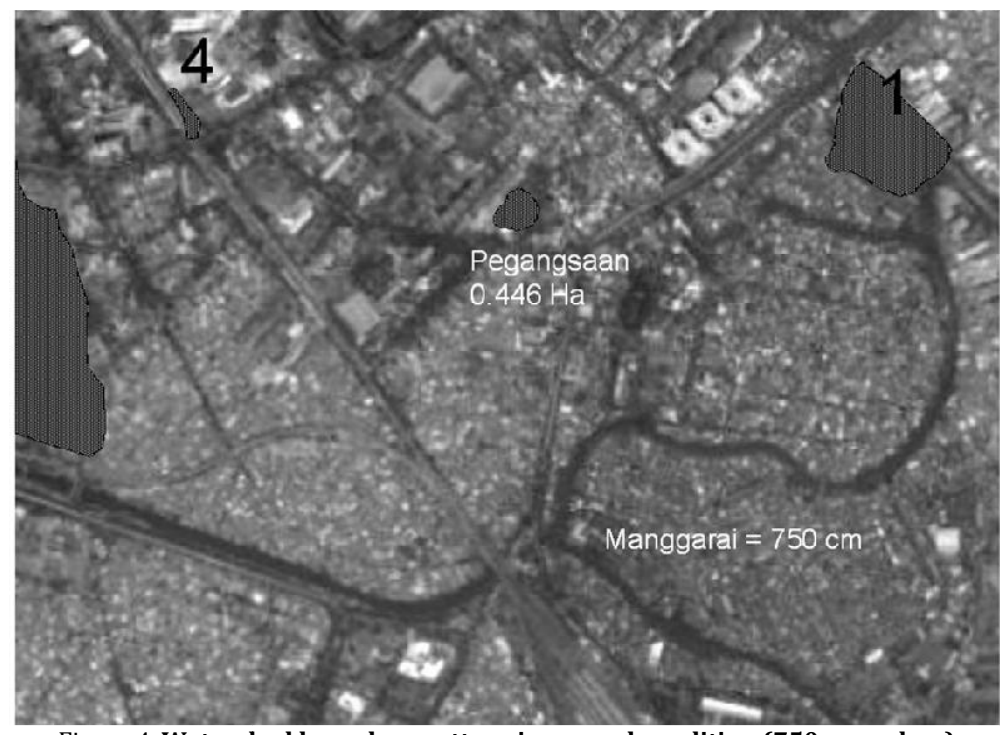

Figure 4. Watershed boundary pattern in normal condition $(750 \mathrm{~cm}$ or less)

The measured potential area of the sample area correlated with water level height increase at $10 \mathrm{~cm}$ interval up to $100 \mathrm{~cm}$ is summarized in Table 1 . When the water level rise from $750 \mathrm{~cm}$ to $800 \mathrm{~cm}$, the potentially flooded area is predicted to grow to almost 1 hectare, and after a simulated increase of water level at Manggarai Gate, the potentially flooded area grow more than fourfold from its original size to more than 1.8 hectares. The predicted potential is shown in Figures 5(a) and (b).

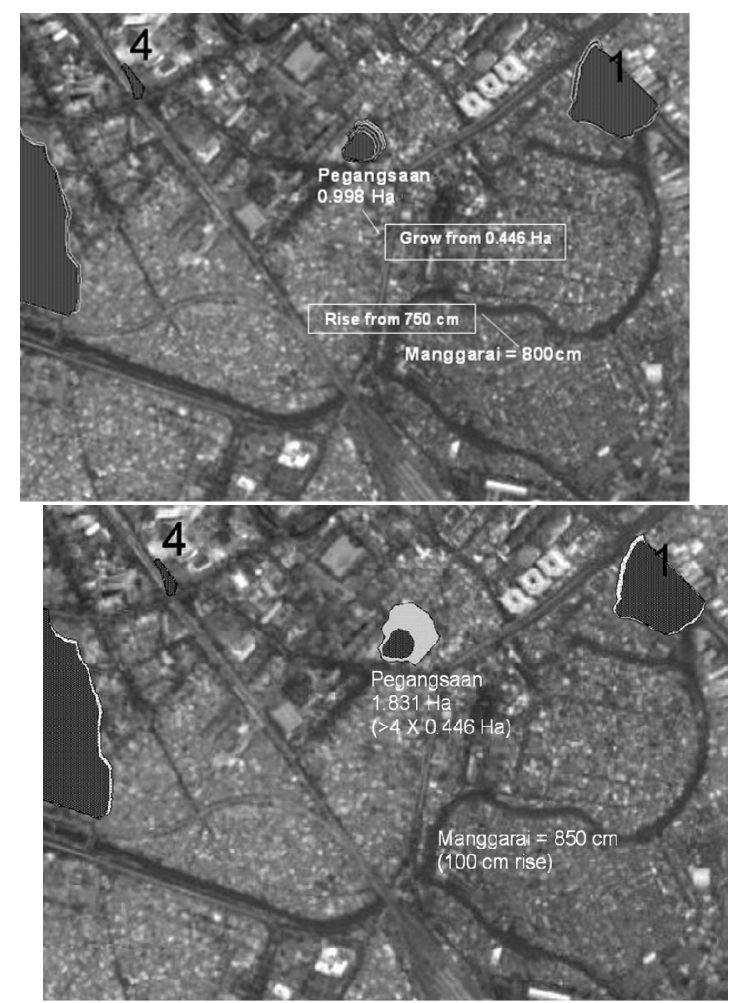

Figure 5. Watershed boundary pattern in flooded condition (a) at $800 \mathrm{~cm}$, and (b) at $850 \mathrm{~cm}$ 


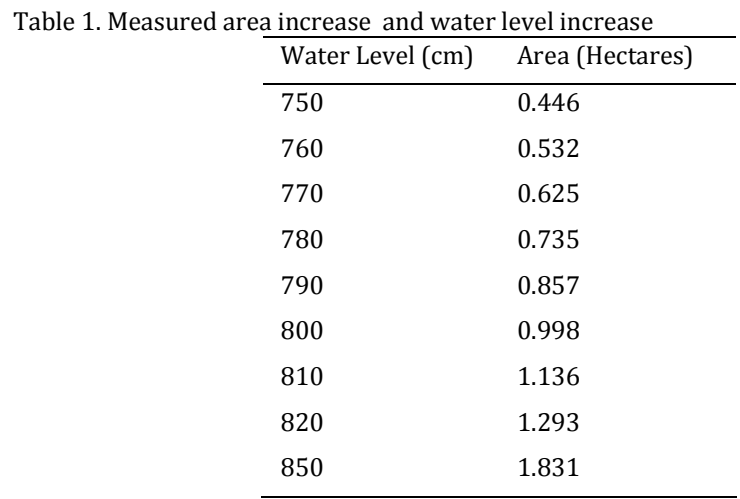

\subsection{Water Level Imaging Sensor}

Unlike most other systems that use ultrasound sensors, which is depended on the sonic reflection of the float and prone to disturbances, this system proposes the use of optical imaging sensor to detect the water level at the riverbank. The images taken from the sensor is then connected to the flood potential area maps as described previously. Sample from imaging sensor test on simulated riverbank measurement is shown in Figure 6(a) and the reading in Figure 6(b).
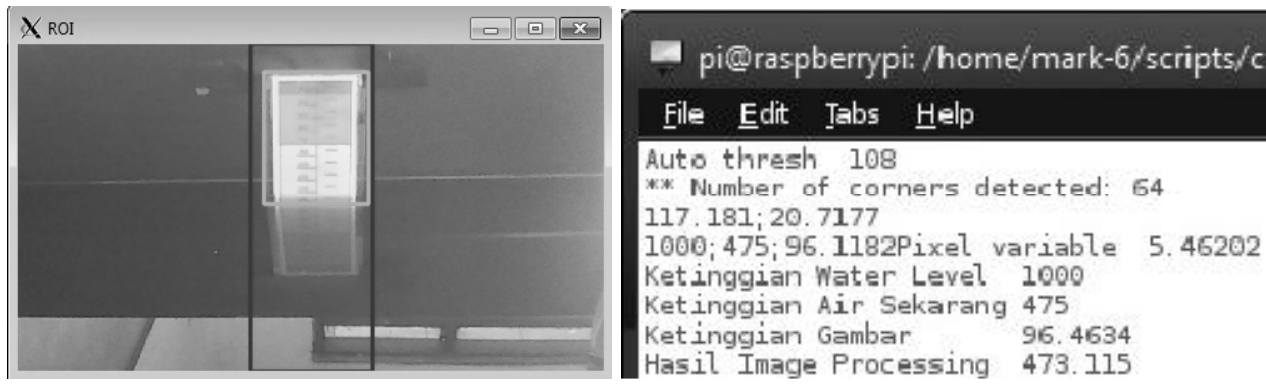

\section{File Edit Tabs Help}

Auto thresh 108

*:. Number of corners detected: 64

$117.181 ; 20.7177$

$1000 ; 475 ; 96.1182$ pixel variable 5.46202

Ketinggian Water Level 1000

Ketinggian Air Sekarang 475

Ketinggian Gambar $\quad 96.4634$

Hasil Image Processing 473. 115

Figure 6. Image sensor test (a) image, and (b) measurement reading

\section{Conclusions}

From the data processing in this discussion, it can be concluded that since most of the areas near a river is of low elevation, these areas are categorized as very potent of being flooded, especially if the area is surrounded by higher grounds. Image segmentation based on watershed morphology can indicate patterns that correspond with known water bodies; therefore, if there is no known corresponding water body nearby, it can be regarded as flood potential. From the simulation, the imaging sensor can detect the height of the water level, and $100 \mathrm{~cm}$ water level rise results in fourfold increase of potentially flooded area from 0.446 hectares to 1.831 hectares.

\section{References}

Hess, L.L.; Melack, J.M.; Filoso, S.; and Wang, Y. (1995). "Delineation of Inundated Area and Vegetation Along the Amazon Floodplain with the SIR-C Synthetic Aperture Radar", IEEE Transactions On Geoscience And Remote Sensing, Vol. 33, No. 4, July 1995, pp. 896-904

Kristijono, A. (1994). "Erosion Rate Estimation Method with TIN-Based Digital Elevation Model”, Remote Sensing \& Geographic Information Systems Yearbook, 1994. 
Mason, D.C.; Davenport, I.J.; Neal, J.C.; Schumann, G.J.-P; and Bates, P.D. (2012). “Near Real-Time Flood Detection in Urban and Rural Areas Using High-Resolution Synthetic Aperture Radar Images", IEEE Transactions On Geoscience And Remote Sensing, Vol. 50, No. 8, August 2012, pp. 3041-3052

Sun, D., Yu, Y., and Goldberg, M.D. (2011). “Deriving Water Fraction and Flood Maps From MODIS Images Using a Decision Tree Approach”, IEEE Journal Of Selected Topics In Applied Earth Observations And Remote Sensing, Vol. 4, No. 4, December 2011, pp. 814-825

Tateishi, R.; Sumantyo, J.T.S. (2012). "Development of geospatial data sharing/overlay system CEReS Gaia -," Geoscience and Remote Sensing Symposium (IGARSS), 2012 IEEE International , vol., no., pp.558,561, 22-27 July 2012

Wihartini; Pramusinto, W.; and Riyanto, I. (2012). "Mobile System to Support Flood Area Information Distribution. Case Study: Central Jakarta Area", The 5th Indonesia-Japan Joint Scientific Symposium (IJJSS), Chiba University, Japan, 2012 